\title{
Effect of Sodium intake on the Excretion of Urinary Natriuretic Factor in Essential Hypertensives
}

\author{
Toshio MORISE, Isamu MIYAMORI, *Sensyu HIFUMi, Shinya OKAMOTO, \\ Masatoshi IKEDA, Yosiyu TAKEDA, Hideo KOSHIDA, \\ SYUITIRo YASUHARA AND RYOUYU TAKEDA
}

\author{
The Second Department of Internal Medicine School of Medicine, \\ Kanazawa University, Kanazawa 920 \\ *Fukui Junkanki Hospital, Internal Medicine Fukui 910
}

\begin{abstract}
A simplified method for the determination of natriuretic factor in the urine as measured by digoxin-like substance was studied. Digoxin-like substance in the urine was estimated by RIA using anti-digoxin antibody after being extracted by reversed phase cartridge column but without gel filtration. The values found by radioimmunossay (RIA) yielded a significant correlation with those of the inhibitory effect of Na-K-ATPase activity which was measured by biochemical assay as described by Hamlyn et al.

Using this RIA method, the effect of salt intake on natriuretic factor in urine was studied in patients with essential hypertention. The natriuretic factor on a high sodium diet $(\mathrm{NaCl} 20 \mathrm{~g} /$ day for three days $)$ increased approximately 1.5 times, as compared to those on a low sodium diet $(\mathrm{NaCl}$ $3 \mathrm{~g} /$ day $)(\mathrm{p}<0.05)$. The Natriuretic factor showed a positive correlation with urinary $\mathrm{Na}$ excretion $(\mathrm{P}<0.050)$ when the patients were placed on ad. lib. sodium diet. From these results, it is suggested that secretion of natriuretic factor in the urine might be regulated in part by salt intake.
\end{abstract}

In a cross-circulation experiment, de Wardener et al., 1961 first observed that the extracellular fluid (ECF) volume expansion causes marked natriuresis whicn may be produced by a hormone-like substance in the circulating blood. Since then biological and immnological properties of this hormone-like substance such as an inhibitory effect on activity of Na-K-ATPase (Gonic et al., 1977) and cross-reactivity with digoxin antibody (Gruber et al., 1980) have been disclosed. Various methods have been de- veloped and are used for the determination of this substance. However, these methods included troublesome purification procedures and this hampers clinical application. In the present study, we have established a simple and rapid method for the determination of natriuretic factor in human urine, using its immunological property to cross react with anti-digoxin antibody. We also studied the effect of salt balance on the natriuretic factor in human urine. 


\section{Material and Methods}

\section{Methods}

$200 \mathrm{ml}$ of urine was adsorbed in a reversed phase cartridge column (SEP-PAK C 18, Waters Co., Ltd., USA) washed with $0.1 \%$ TFA $20 \mathrm{ml}$ and petrolium ether $10 \mathrm{ml}$ and eluted with acetonitril : $0.1 \%$ TFA $(80: 20) 5.0 \mathrm{ml}$. The elute was lyophilized (sample A), and filtered with Sephadex G-25 (Pharmacia Fine Chemicals, Superfine, diameter; $0.9 \mathrm{~cm}$, length; $70 \mathrm{~cm}$, solvent; $0.1 \%$ TFA, Flow rate; $1.2 \mathrm{ml} / \mathrm{min}$, frationation for 5 minutes). Digoxin-like substance in each fraction was determined by RIA. Commercial kits made available by Daiichi Radioisotope Co., Ltd. were used for RIA. RIA yielded a single peak of digoxin-like immunoreactivity after salt fraction (Fig. 1 lower column).
To compare with conventional methods, a $200 \mathrm{ml}$ of urine was lyophylized (sample B) and separated by gel filtration with Sephadex G-25 similarly to sample A. The Gel filtration pattern of sample B showed a single peak of the same site as that of sample A (Fig. 1). Moreover, on comparing treated sample A separating to postsalt fraction by gel filtration (F2 in Fig. 2) and untreated sample A, there was found to be no difference in values by RIA. Namely, as the substance interfering with RIA is removed by extraction with a reversed phase cartridge column, gel filtration might be unnecessary to determine the natriuretic factor as digoxin-like substance by RIA. Thus, for subsequent determinations, only extraction with reversed phase cartridge column but gel filtration was carried out.

Secondly, for the quantitative determination of natriuretic substance, the correlation between the values obtained by RIA using antidigoxin
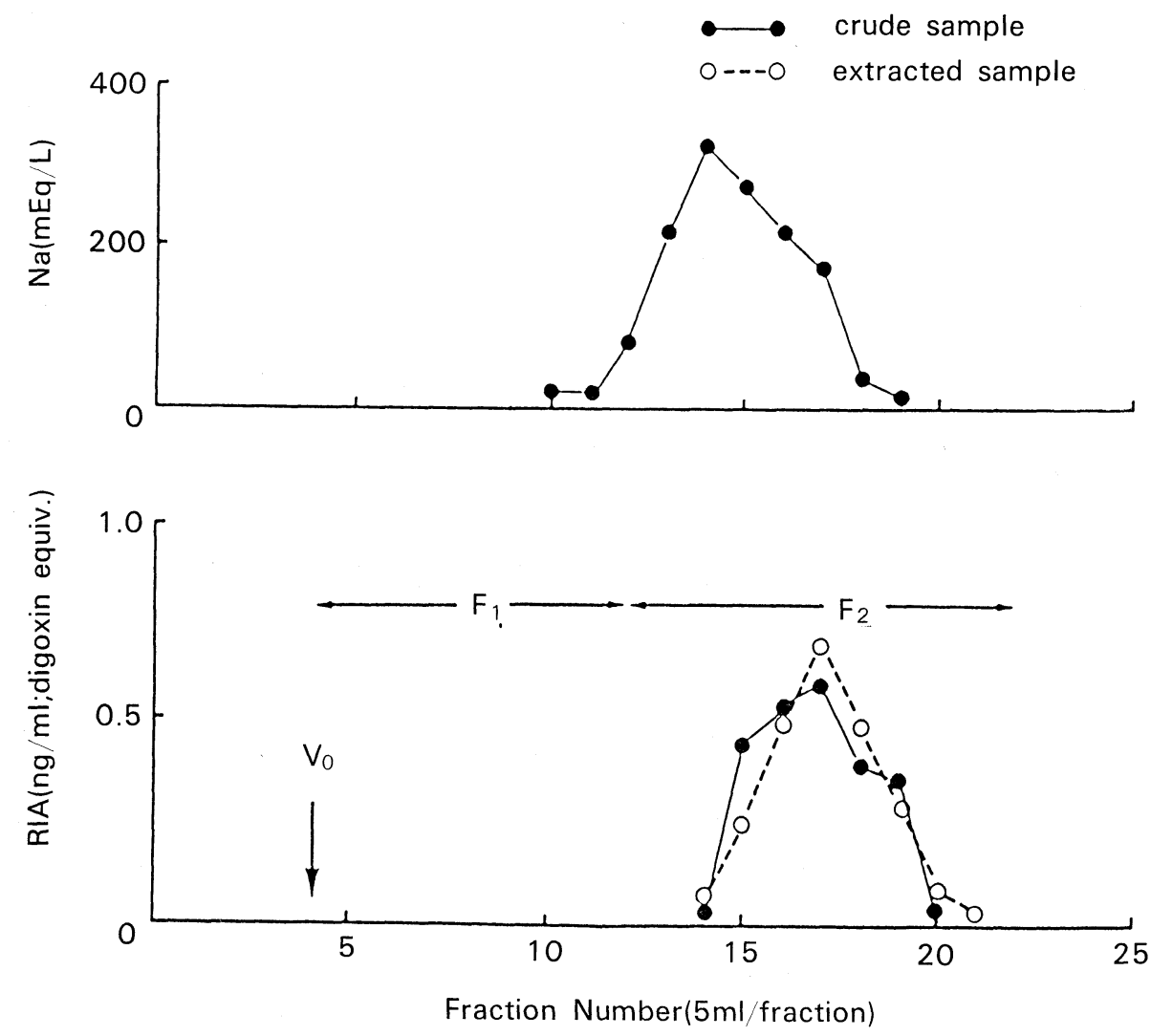

Fig. 1. Gel filtration profiles on Sephadex G-25. 
antibody and the inhibitory effect on Na-KATPase activity was studied. The inhibitory effect on Na-K-ATPase activity was determined according to Hamlyn et al's. method (Hamlyn et al., 1982). In brief, the decreasing ratio was determined as the change in absorbance at $340 \mathrm{~nm}$ by utilizing the change from NADH to NAD coupling the change of ATP to ADP. To assay cocktail ( $\mathrm{KCl} 20 \mathrm{mM}, \mathrm{NaCl} 100 \mathrm{mM}, \mathrm{MgSO}_{4}$ $4.5 \mathrm{mM}$, EGTA $5 \mathrm{mM}, \mathrm{Na}_{2}$ ATP $3 \mathrm{U}$, PEP $1.2 \mathrm{mM}$, NADH $0.25 \mathrm{mM}$, TES-tris $40 \mathrm{mM}, \mathrm{pH} 7.4, \mathrm{LDH}$ $1.2 \mathrm{U}$ and PK $1.2 \mathrm{U}$ in $1.0 \mathrm{ml}$., these reagents were obtained from SIGMA Chemical Company or Oriental Yeast Co., Ltd.) $780 \mu$, distilled water $200 \mu \mathrm{l}$ (control), or sample $200 \mu \mathrm{l}$ was added to make $980 \mu \mathrm{l}$. Then, to this solution, canine kidney Na-K-ATPase suspension $20 \mu$ l (SIGMA Chemical Company, $3 \mu$ g protein) was added and reaction was started at $37^{\circ} \mathrm{C}$. The change in absorbance at $340 \mathrm{~nm}$ was recorded with the time course. Percentage inhibition was calculated by means of the following formula.

$$
100-\frac{\Delta \text { sample } \mathrm{A}_{340} \mathrm{~min}}{\Delta \text { control } \mathrm{A}_{340} \min } \times 100 \text {. }
$$

Calculation of inhibition ratio on Na-Ka-ATPase and RIA using anti-digoxin antibody was carried out in each sample, which was extracted from the urine $200 \mathrm{ml}$ using a reversed phase cartridge column, and the values obtained by these 2 methods were compared. These methods showed a significant positive correlation $(\mathrm{r}=0.855, \mathrm{p}<$ 0.01 ), which passes the original point (Fig. 2). Thus, it was suggested that natriuretic factor in the urine may be evaluated quantitatively RIA using anti-digoxin antibody.

\section{Materials}

Nineteen hospitalized patients with mild or moderate (WHO I-II stage) essential hypertension were studied after informed consent was obtained. They were given low salt diet ( $\mathrm{Nacl} 3 \mathrm{~g} /$ day) for three days and a high salt diet $(\mathrm{NaCl} 20 \mathrm{~g} /$ day $)$ for the subsequent 3 days after ad. lib. diet for about 2 weeks. On the third day of each diet, 24 hour urine was collected and digoxin-like substance and aldosterone in the urine were determined. On the same day, after an overnight fast, the blood was withdrawn and used for the determination of PRA, Plasma aldosterone (p-aldo), serum $\mathrm{Na}$ and $\mathrm{K}$. Urinary aldosterone after hy-

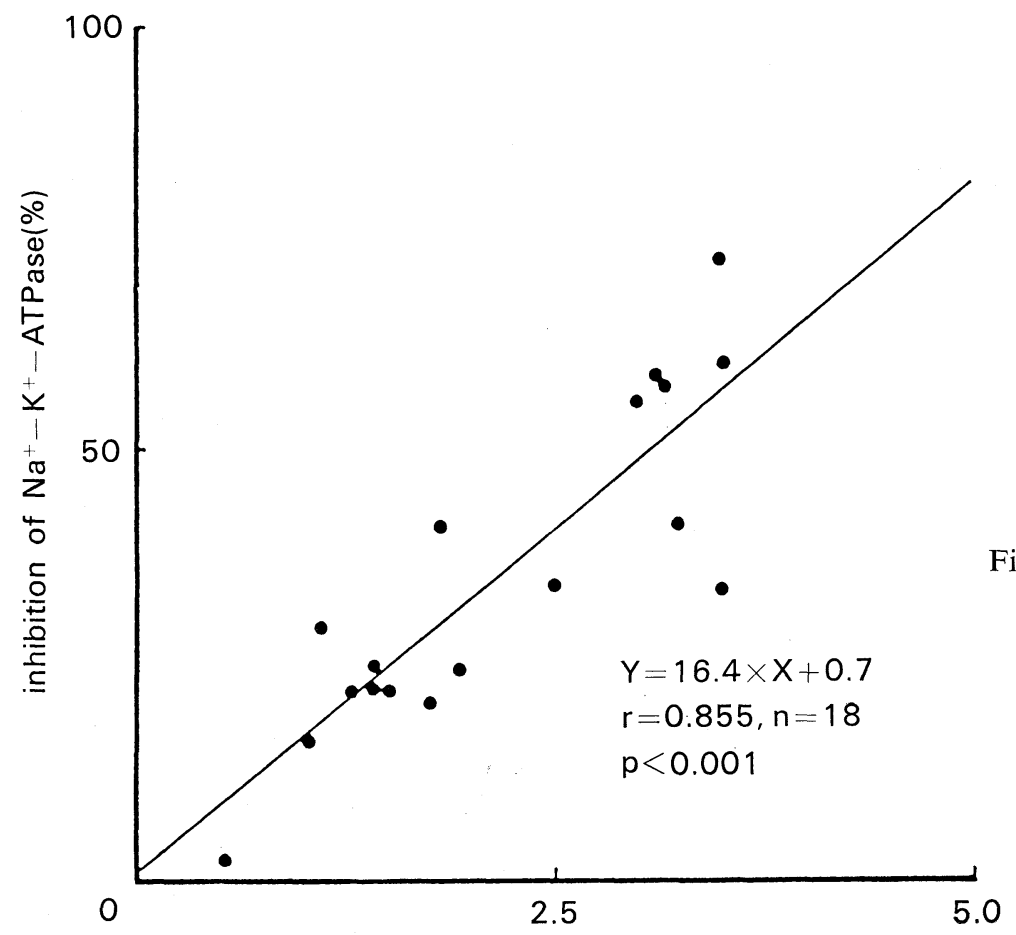

Fig. 2. Correlation between the inhibition of $\mathrm{Na}-\mathrm{K}-\mathrm{ATPase}$ and digoxin-like immunoreactivity. 
Table 1. Clinical Characteristics of patients

\begin{tabular}{llrc}
\hline \hline & $\mathrm{NaCl} 3 \mathrm{~g} /$ day & $\mathrm{NaCl} 20 \mathrm{~g} /$ day \\
\hline \begin{tabular}{l} 
Mean blood pressure \\
\multicolumn{2}{c}{$(\mathrm{mmHg})$}
\end{tabular} & $98.1 \pm 6.6$ & $104.3 \pm 5.6$ \\
$\mathrm{PRA}$ & $(\mathrm{ng} / \mathrm{ml} / \mathrm{h})$ & $4.1 \pm 1.1$ & $0.7 \pm 0.2^{* *}$ \\
$\mathrm{P}-\mathrm{aldo}$ & $(\mathrm{ng} / \mathrm{dl})$ & $16.7 \pm 3.6$ & $6.4 \pm 1.0^{*}$ \\
$\mathrm{~S}-\mathrm{Na}$ & $(\mathrm{mEq} / \mathrm{l})$ & $140.2 \pm 0.9$ & $140.8 \pm 1.1$ \\
$\mathrm{~S}-\mathrm{K}$ & $(\mathrm{mEq} / \mathrm{l})$ & $4.1 \pm 0.3$ & $4.2 \pm 0.2$ \\
$\mathrm{U}_{\mathrm{NaV}}$ & $(\mathrm{mEq} / \mathrm{D})$ & $39.3 \pm 4.9$ & $182.9 \pm 21.7 * *$ \\
$\mathrm{U}_{\mathrm{K}} \mathrm{V}$ & $(\mathrm{mEq} / \mathrm{D})$ & $34.6 \pm 2.9$ & $41.9 \pm 4.1$ \\
$\mathrm{U}_{\mathrm{Cr}} \mathrm{V}$ & $(\mathrm{mg} / \mathrm{D})$ & $749.6 \pm 93.7$ & $748.7 \pm 79.5$ \\
\hline
\end{tabular}

Mean \pm SE. * : p $<0.05$,

$* *: \mathrm{p}<0.01 \mathrm{VS} \mathrm{NaCl}$ restricted state

drolysis with $1 \mathrm{~N} \mathrm{HCl}$ Overnight, PRA and p-aldo were measured by RIA as previously reported (Takeda et al., 1976). For statistical analysis, Student's $t$-test was used and $\mathrm{p}<0.05$ was defined as significant.

\section{Results}

Following the increase in salt intake from $3 \mathrm{~g} /$ day to $20 \mathrm{~g}$ /day, the mean blood pressure rose slightly, PRA, PA and urinary aldosterone decreased significantly and the urinary excretion of $\mathrm{Na}$ increased significantly (Table 1).

Digoxin-like substance (DLS) in the urine increased from $19.0 \pm 3.0 \mathrm{ng} /$ day on low salt diet to $31.9 \pm 3.7 \mathrm{ng} /$ day on high salt diet ( $<<0.05$, Fig. 3).

Furthermore, the relationship between urinary excretion of digoxin-like substance and sodium, aldosterone and age was studied in the duration of salt intake ad. lib. DLS in the urine showed significantly positive correlation with urinary excretion of sodium $(\mathrm{r}=0.5886, \mathrm{p}<0.01)$ and there was a significantly negative correlation with urinary excretion of aldosterone $(\mathrm{r}=-0.4653, \mathrm{p}<$ 0.05 , Fig. 4).

In the present study on a hypertensive patient without apparent nephropathy, we did not observe an age-related change in DLS (per day and per g creatinine, Fig. 5).

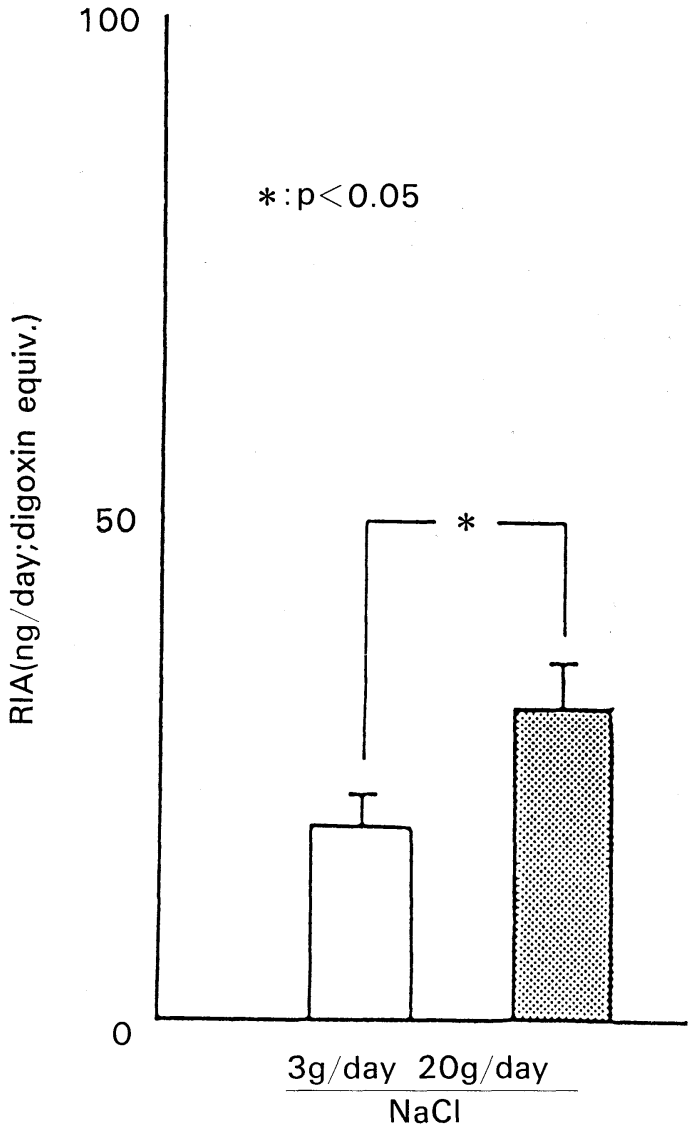

Fig. 3. Effect of change in $\mathrm{Na}$ balance on urinary digoxin-like substance.

\section{Discussion}

A bioassay method (Clarkson et al., 1976) using rats, a method using inhibitory effect on Na-K-ATPase activity (Gonic et al., 1977) and RIA using an anti-digoxin antibody (Klingmuller et al., 1982) have been used conventionally for the determination of natriuretic factor. However, in the case of measuring it in urine, these methods employ lyophilization of massive urine and if necessary, many purification steps such as gel filtration, desalination, strict adjustment of $\mathrm{pH}$ and ion concentration in the solution. The present method using reversed phase cartridge column we have developed is a 
simple procedure which enables condensation, desalination, deproteinzation to be done at one time and removes substances that may possibly interfere with RIA. Although RIA is a convenient method, it is not known whether it is consistent with other methods or not. Although it has been reported that the bioassay method gives results consistent with its inhibitory effect on Na-K-ATPass (Gonic et al., 1977, Hillyard et al., 1976) no correlation between RIA and the in- hibitory effect on Na-K-ATPase activity has been demonstrated. As shown in Fig. 2, there was a significant positive correlation between the RIA and the methods using $\mathrm{Na}$ $\mathrm{K}$-ATPase. This suggests that the natriuretic factor in the urine can be estimated quantitatively by RIA using anti-digoxin antibody.

Expanded ECF is thought to be a major factor which regulates the natriuretic factor. Bioassay showed an increase in the natriuretic factor in the blood from dogs and
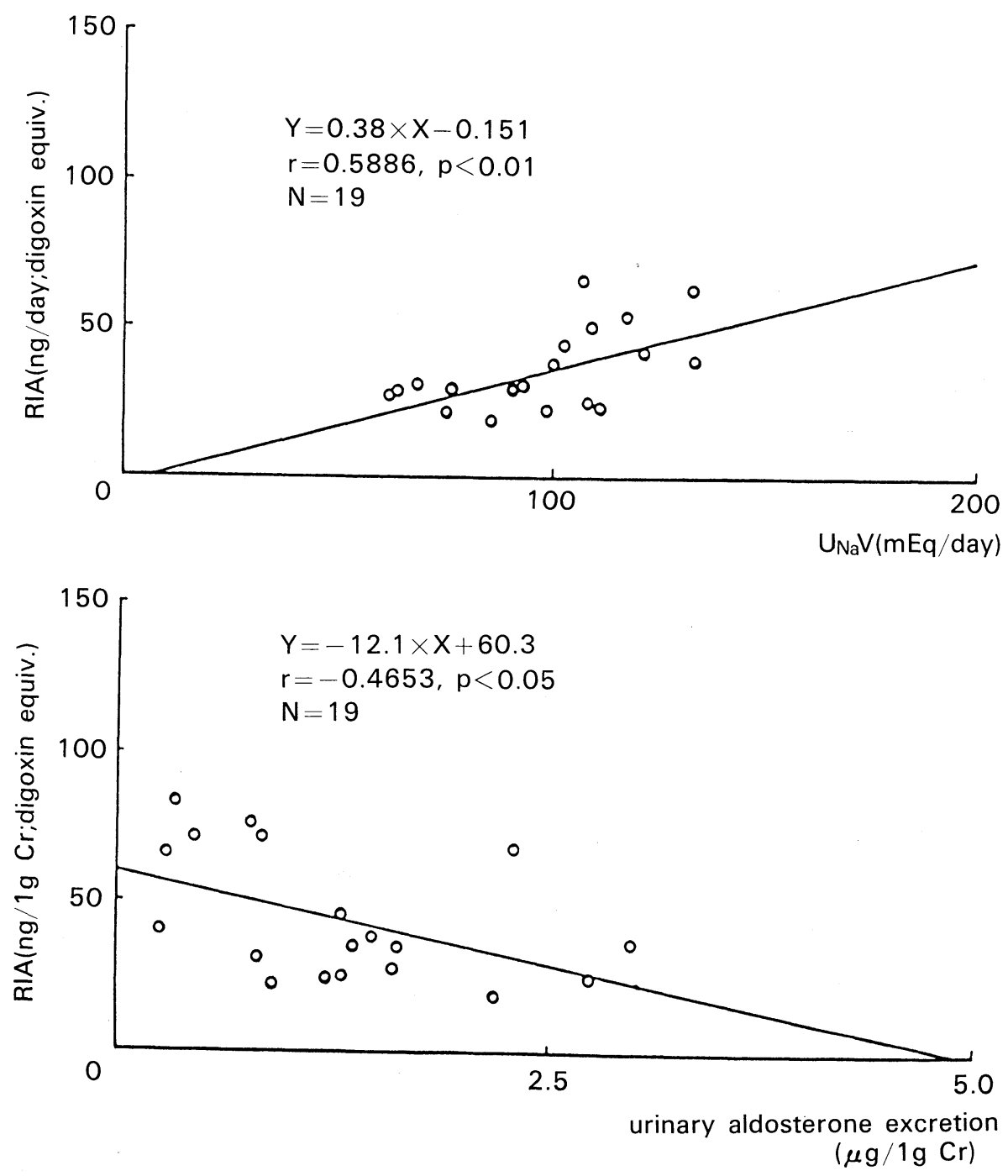

Fig. 4. Correlation between digoxin-like substance and urinary $\mathrm{Na}$ or aldosterone excretion. 
rats treated with blood transfusion (Hamlyn et al., 1982, Knock et al., 1980), or in the urine of humans (Clarkson et al., 1976, Klingmuller et al., 1982) who were given a high salt diet $(\mathrm{Na} ; 300 \mathrm{mEq} /$ day $)$. In our study, a diet with $20 \mathrm{~g} /$ day of salt for 3 days produced a 1.5 -fold increase in DLS in the urine compared to the period with $3 \mathrm{~g} /$ day of salt. de Wardener et al. (1981) demonstrated a 25 time increase in human subjects when a high salt diet was given. This difference may be due to (Clarkson et al., 1976) a difference in assay methods or (Clarkson et al., 1970) a difference in the salt loading period i. e. 3 days in our study and 5 days in de Wardner's study. Although we did not compare our RIA method with de Wardener's cytochemical technique for the determination of Na-K-ATPase activity, the possibility of the different assay methods cannot be neglected in view of our finding that the inhibitory effect on NA-K-ATPase using the conversion of NADH to NAD showed a significant correlation with the
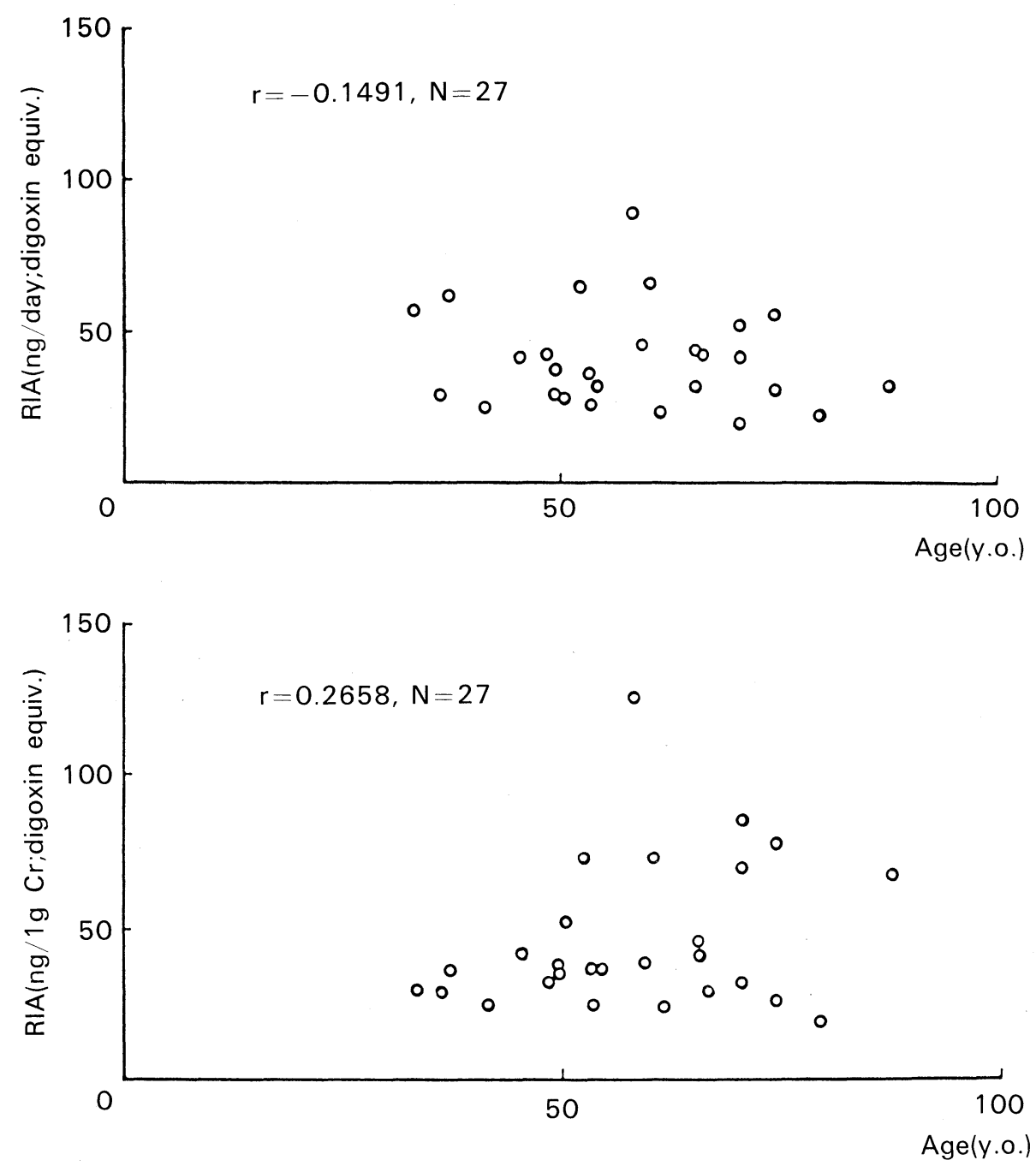

Fig. 5. Correlation between digoxin-like substance and age. 
RIA method but the slope of its regression line is as sharp as 16.4 (Fig. 2). Concerning the duration of the salt load, this study lasted only 3 days, but there is a tendency for DLS in the urine to in craese more from 3rd day in preliminary examination with small cases, and the difference between de Wardener's results and ours may be also possibly due to the fact that in the duration of the salt load was different.

Digoxin-like substance showed a positive correlation with urinary $\mathrm{Na}$ excretion and is may indicate that $\mathrm{Na}$ balance plays an important role in the regulation of this substance. In addition, it showed a negative correalation with urinary aldosterone, but it is not known whether aldosterone per se effects DLS excretion or not.

\section{Acknowledgements}

This work was supported in part by a grant from the ministry of Health and Welfare "Disorders of Steroid Hormones" Research Committee, Japan, 1984.

\section{References}

Clarkson, E. M., S. M. Raw and H. E. de Wardener (1976). Two natriuretic substances in extracts of urine from normal man when salt-depleted and salt-loated. Kidney. Int. 10, 381-394.

Clarkson, E. M., L. B. Talner and H. E. de Wardener (1970). The effect of plasma from blood volume expanded dogs on sodium, potassium and PAH transport of renal tubule fragments. Clin. Sci. 38, 617-627.

de Wardener, H. E., G. A. MacGregor, E. M. Clarkson, J. Alaghband-Zadeh, L. Bittensky J. Chayen (1981). Effect of sodium intake on ability of human plasma to inhibit renal $\mathrm{Na}$ K-ATPase in vitro. Lancet. 21, 411-414.

de Wardener, H. E., I. H. Mills, W. F. Clapham and C. J. Hayter (1961). Study on the efferent mechanism of the sodium diuresis which follows the administration of intravenous saline in the dog. Clin. Sci. 21, 249-258.

Gonic, H. C., H. J. Kramer, W. Paul and E. Lu (1977). Circulating inhibitor of sodium-potassium-activated adenosine triphosphatase after expansion of extracellular fluid volume in rats. Clin. Sci. Mol. Med. 53, 329-334.

Gruber, K. A., J. M. Whitaker and V. M. Buckalew Jr. (1980). Endogenous digitalis-like substance in plasma of volume-expanded dogs. Nature. 287 , 743-745.

Hamlyn, J. M., R. Ringel, J. Scheffer, P. D. Levinson, B. P. Hamilton, A. A. Kowarski and M. P. Blaunstein (1982). A circulating inhibitor of $(\mathrm{Na}+\mathrm{K})$ ATPase associated with essential hypertension. Nature 300, 650-652.

Hillyard, S. D., E. Lu and C. Gonic (1976). Further characterization of the natriuretic factor derived from kidney tissue of volume-expanded rats. Cir. Res. 38, 250-255.

Klingmuller, D., E. Weiler and H. J. Kramer (1982). Digoxin-like natriuretic activity in the urine of salt loaded healthy subjects. Klin. Woochenschr. 60, 1249-1253.

Knock, C. A. (1980). Further evidence in vivo for a circulating natriuretic substance after expanding the blood volume in rats. Clin. Sci. 59, 423-433.

Takeda, R., S. Morimoto, K. Uchida and I. Miyamori (1976). Changes in plasma renin activity and plasma aldosterone in the induced paralytic attack of thyrotoxic periodic paralysis. Acta. Endocrinol. (kbh), 82, 715-727 